\section{BMJ Open} Ophthalmology

\title{
Expert practice patterns and opinions on corneal cross-linking for infectious keratitis
}

\author{
Yen C Hsia, ${ }^{1}$ Caitlin A Moe, ${ }^{2}$ Thomas M Lietman, ${ }^{1,2}$ Jeremy D Keenan, ${ }^{1,2}$ \\ Jennifer Rose-Nussbaumer ${ }^{1}$
}

To cite: Hsia YC, Moe CA, Lietman TM, et al. Expert practice patterns and opinions on corneal cross-linking for infectious keratitis. BMJ Open Ophthalmology 2018;3:e000112. doi:10.1136/ bmjophth-2017-000112

- Additional material is published online only. To view please visit the journal online (http://dx.doi.org/10.1136/ bmjophth-2017-000112).

Received 18 August 2017 Revised 5 January 2018 Accepted 15 January 2018

\section{Check for updates}

${ }^{1}$ Department of Ophthalmology, University of California, San Francisco, California, USA ${ }^{2}$ Francis I Proctor Foundation, University of California, San Francisco, California, USA

Correspondence to Dr Jennifer Rose-Nussbaumer; jennifer.rose-nussbaumer@ ucsf.edu

\section{ABSTRACT}

Objective To assess the current opinion and practice patterns from cornea experts regarding the benefit of corneal cross-linking (CXL) for infectious keratitis (IK). Methods and analysis An international survey was distributed to corneal specialists via an internet survey. The survey data collected were analysed with descriptive statistics.

Results A survey was sent to 190 recipients, and $29(15 \%)$ respondents completed the survey with an average of 7 years' experience using CXL. A majority of respondents $(66 \%)$ used CXL to treat IK due to bacterial, fungal, protozoan or unknown aetiology. Main indications to use $\mathrm{CXL}$ as adjuvant therapy were worsening infiltrate diameter or depth despite therapy (74\%), followed by antibiotic resistance (68\%), corneal thinning (53\%), poor compliance with medication (26\%) and other reasons (21\%). Most respondents felt CXL would be at least moderately helpful as an adjuvant therapy for bacterial $(96 \%)$ or fungal $(75 \%)$ keratitis; about half $(46 \%)$ thought it would be helpful for acanthamoeba keratitis. As sole therapy, fewer respondents believed CXL would be at least moderately helpful to treat bacterial $(75 \%)$, fungal $(58 \%)$ and acanthamoeba (43\%) keratitis.

Conclusion The survey offered insights into current expert practices and opinions of using CXL as therapy for IK. The results of this survey serve to guide in the design of future clinical studies.

\section{INTRODUCTION}

Infectious keratitis (IK) is a major cause of visual impairment and blindness worldwide. ${ }^{1}$ Causative organisms include bacteria, fungi and protozoa; treatment is empiric until the infectious organism is identified. Delayed initiation of appropriate therapy can result in poor visual outcomes in up to $30 \%$ of IK cases. ${ }^{2}$ Antibiotic resistance, drug availability and ocular toxicity complicate treatment regimens for the different types of keratitis and practice patterns vary internationally. ${ }^{2-6}$

Corneal cross-linking (CXL) may benefit patients with infectious corneal ulcers by reducing inflammation and inactivating infectious organisms simultaneously. CXL is currently used as a treatment for corneal ectatic disorders such as keratoconus and post-LASIK ectasia and has been shown to stabilise the cornea and allow it to retain

\section{Key messages}

What is already known about this subject?

In vitro studies and case series have suggested that adjuvant corneal cross-linking may have a role in the treatment of infectious keratitis.

What are the new findings?

- Experts believe that corneal cross-linking is a beneficial adjuvant for treating infection and stabilizing keratolysis, but that it is more effective in bacterial infections than fungal or acanthameoba.

How might these results change the focus of research or clinical practice?

A well-designed randomized controlled trial is necessary to establish the role of corneal crosslinking in the treatment of corneal ulcers.

its shape..$^{7-9}$ Photoactivation of riboflavin with UV light results in release of reactive oxygen species that promote chemical covalent bond formation between adjacent collagen molecules. ${ }^{9} 10$ This may strengthen the cornea, increase resistance of corneal tissue to enzymatic degradation and reduce the risk of corneal melting and perforation which can complicate IK. ${ }^{10} 11$ Reactive oxygen species are also thought to have an antiseptic effect against a broad range of pathogens. ${ }^{12}$ Although there have been three small randomised controlled trials to evaluate the effect of CXL in the treatment of IK, the limitations of these clinical trials and mixed results leave the question unanswered. ${ }^{13-15}$ In this survey, we assess corneal experts' current practices and opinions regarding adjuvant CXL for IK.

\section{METHODS}

A survey with questions about the use of CXL for IK was emailed to experts to assess their perspectives and experiences. Experts were identified through a search of PubMed for manuscripts published between January 2009 and May 2017 in English-language journals that included the terms 'cornea', 'infectious keratitis' and variations of 'cross-linking' in the title or abstract. Authors' email addresses 


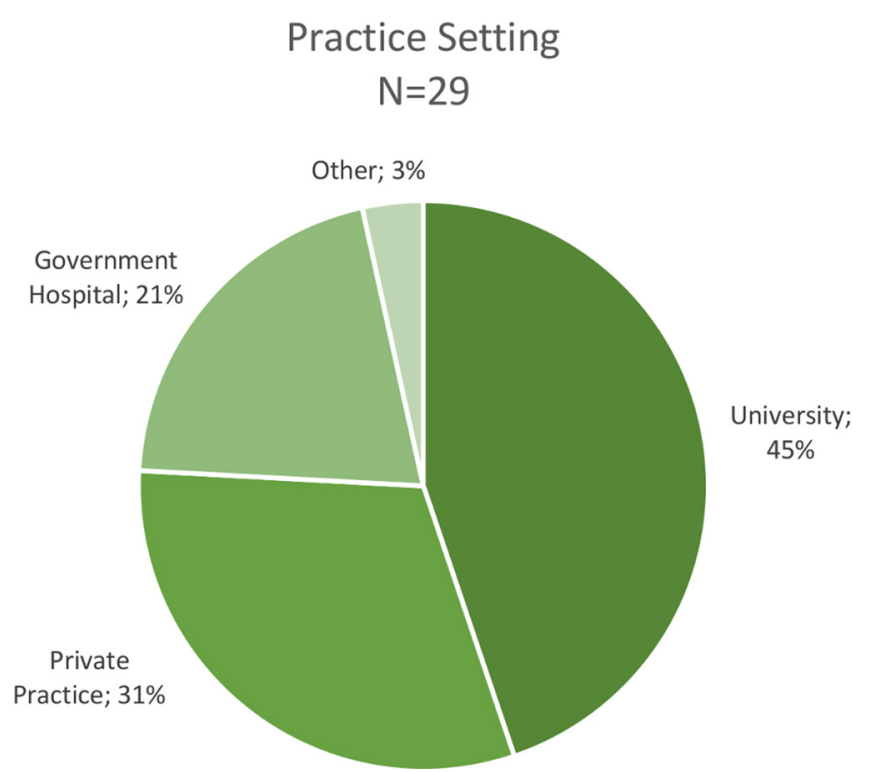

Figure 2 Respondents practice setting.

were extracted with a Perl ${ }^{16}$ programme from corresponding author information.

An email with an introduction to the survey, a consent document and an individualised, anonymous survey URL was sent to each participant email address through the Research Electronic Data Capture (REDCap) data collection tool. The initial invitation was sent by email in January 2016 and four reminder emails were sent to participants who had not responded. The survey was open for a total of 8 weeks.

The questionnaire consisted of the following sections: (1) demographic information, (2) clinical experience with cross-linking for IK, (3) ideal practice using CXL for IK (online supplementary file). Respondents who

\section{Country of Practice \\ $\mathrm{N}=29$}

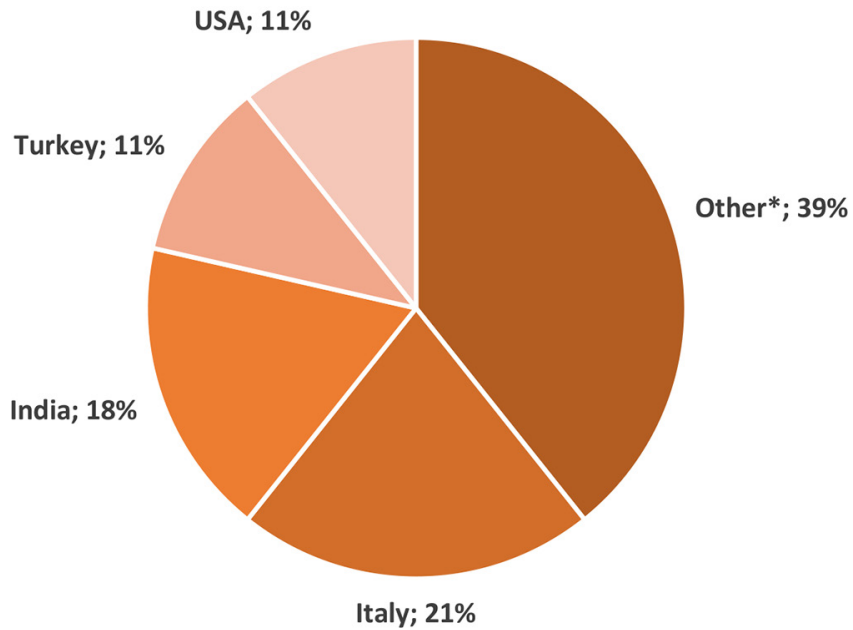

Figure 1 Respondents' country of practice. *Australia, Austria, Brazil, Colombia, Denmark, France, Greece, Pakistan, Portugal, Sweden, Switzerland and UK. reported experience treating IK with cross-linking were posed an additional section regarding (4) the utility of cross-linking for each type of infectious organism for which they had experience. Respondents were given the option to waive anonymity of their survey response to be included in the acknowledgements section.

Results were analysed using Stata V.14 (Stata, College Station, Texas, USA). This research adhered to the tenets of the Declaration of Helsinki.

\section{RESULTS}

\section{Demographics}

A literature search of publications on CXL identified 190 unique, valid email addresses. Twenty-nine (15.3\%) recipients completed the survey. All survey recipients were cornea specialists, with subspecialty training in cornea only $(n=7 ; 24 \%)$, cornea and refractive $(n=19$; $66 \%)$ and other subspecialties $(\mathrm{n}=3 ; 10 \%)$. Respondents were from 16 countries, with more from Italy $(n=6 ; 21 \%)$ and India $(n=5 ; 17 \%)$ and others from USA and other countries in Europe, South America, the Middle East and Australia (figure 1). The most common practice setting of respondents was academic $(13 / 29 ; 45 \%)$, followed by private practice $(9 / 29 ; 31 \%)$ and government hospitals $(6 / 29 ; 21 \%)$ (figure 2$)$. The average (median) number of years in practice was 15 years (IQR 8,25 years) with an average (median) of 7 years of experience using CXL on patients (IQR 5, 9years).

The vast majority of respondents reported having used CXL for any indication in their clinical practice (28/29; $97 \%)$. More specifically, CXL was used 1-50 times (34\%), $51-150$ times $(28 \%)$ or more than 150 times $(34 \%)$ in the past 12 months.

\section{Current practices}

Table 1 summarises respondents' current practices and experience using CXL. The majority of respondents $(\mathrm{n}=19 ; 68 \%)$ had used CXL to treat a patient with IK. Of these respondents, organisms treated with CXL were diverse and included bacterial ulcers $(16 / 19 ; 84 \%)$, fungal ulcers $(13 / 19 ; 68 \%)$, acanthamoebic ulcers $(12 / 19 ; 63 \%)$ as well as microbial keratitis of unknown aetiology $(5 / 19 ; 26 \%)$. The survey did not ask about viral keratitis.

The main indications reported for using CXL for IK were worsening infiltrate diameter or depth despite therapy $(14 / 19 ; 74 \%)$, followed by antibiotic resistance $(13 / 19 ; 68 \%)$, corneal thinning $(10 / 19 ; 53 \%)$, poor compliance with medication $(5 / 19 ; 26 \%)$ and other reasons $(4 / 19 ; 21 \%)$ (table 1$)$. Most experts (9/19; $47 \%)$ performed CXL 1-4 weeks after the onset of the ulcer, 37\% (7/19) performed after 4 weeks of onset and $16 \%(3 / 19)$ performed within 1 week of onset. Respondents performed CXL for IK both in the operating room $(13 / 19 ; 68 \%)$ and in the outpatient clinic $(8 / 19$; $42 \%)$. 
Table 1 Respondents' experience with cross-linking for IK

\begin{tabular}{lr}
\hline Survey response & \multicolumn{1}{l}{$\mathbf{n / N}(\%)$} \\
\hline Used CXL ever & $28 / 29(97 \%)$ \\
\hline Used CXL for IK & $19 / 28(68 \%)$ \\
\hline Think CXL can be useful for IK & $25 / 28(89 \%)$ \\
\hline Experience with CXL treating IK by type & \\
\hline \multicolumn{1}{l}{ Bacterial } & $16 / 19(84 \%)$ \\
\hline Fungal & $13 / 19(68 \%)$ \\
\hline Acanthamoeba & $12 / 19(63 \%)$ \\
\hline Unknown organism & $5 / 19(26 \%)$ \\
\hline Indications for using CXL for IK & \\
\hline \multicolumn{1}{l}{ Worsening infiltrate } & $14 / 19(74 \%)$ \\
\hline Antibiotic resistance & $13 / 19(68 \%)$ \\
\hline Corneal thinning & $10 / 19(53 \%)$ \\
\hline Poor medication compliance & $5 / 19(26 \%)$ \\
\hline Other & $4 / 19(21 \%)$ \\
\hline
\end{tabular}

CXL, corneal cross-linking; IK, infectious keratitis.

\section{Ideal practices}

Table 2 describes respondents' opinions on ideal practices for CXL for IK. Of the respondents that thought CXL could be useful to treat IK, 13/24 (54\%) said that

\begin{tabular}{lc}
\hline $\begin{array}{l}\text { Table } 2 \text { Ideal practices of cross-linking for infectious } \\
\text { keratitis }\end{array}$ & $\mathrm{n} / \mathbf{N}(\%)$ \\
\hline Survey response & \\
\hline $\begin{array}{l}\text { Ideal timing* } \\
<1 \text { week }\end{array}$ & $11 / 24(46 \%)$ \\
\hline $1-4$ weeks & $9 / 24(38 \%)$ \\
\hline$>4$ weeks & $0 / 24(0 \%)$ \\
\hline Unsure & $4 / 24(17 \%)$ \\
\hline Ideal ulcer location for CXL* & \\
\hline Central & $6 / 24(25 \%)$ \\
\hline Peripheral & $1 / 24(4 \%)$ \\
\hline Does not matter & $13 / 24(54 \%)$ \\
\hline Unsure & $4 / 24(17 \%)$ \\
\hline CXL beneficial by infiltrate size & \\
\hline Small & $17 / 24(71 \%)$ \\
\hline Medium $\dagger$ & $16 / 23(70 \%)$ \\
\hline Large† & $8 / 23(35 \%)$ \\
\hline Would use CXL for corneal thinning & $15 / 25(60 \%)$ \\
\hline Would use CXL for non-healing ulcer & $12 / 25(48 \%)$ \\
\hline Main benefits of CXL & \\
\hline Microbial eradication & $21 / 25(84 \%)$ \\
\hline Prevention of corneal thinning & $15 / 25(60 \%)$ \\
\hline Other benefits & $3 / 25(12 \%)$ \\
\hline
\end{tabular}

*One respondent with missing data.

†Two respondents with missing data.

$\mathrm{CXL}$, corneal cross-linking. the ideal ulcer location to maximise benefit of CXL does not matter, while others $(6 / 24 ; 25 \%)$ felt a centrally located (central $4 \mathrm{~mm}$ ) ulcer would benefit from CXL the most and 4/24 (17\%) were unsure about the ideal ulcer location. Most respondents felt CXL would be beneficial for infections with small $(17 / 24 ; 71 \%)$ and medium-sized $(16 / 23 ; 70 \%)$ infiltrate diameters but fewer $(8 / 23 ; 35 \%)$ thought CXL would be beneficial for large infiltrates. When asked about when CXL should be ideally performed after the onset of IK, $46 \%(11 / 24)$ of respondents reported $<1$ week of onset of the ulcer, $38 \%$ (9/24) reported 1-4weeks of onset and 17\% (4/24) were unsure. A large majority $(21 / 25 ; 84 \%)$ of respondents reported that the main benefit of CXL for IK would be microbial eradication, and 15/25 (60\%) of respondents reported CXL would be beneficial in the prevention of corneal thinning.

Table 3 outlines how respondents felt about CXL as either an adjuvant therapy (in addition to microbial therapy) or as the sole therapy. The majority of respondents $(25 / 28 ; 89 \%)$ reported that they thought CXL would be useful in treating IK, although responses to follow-up questions showed that opinions varied by type of organism. Most respondents reported that CXL as an adjuvant therapy would be at least moderately effective for bacterial keratitis $(23 / 24 ; 96 \%)$ or fungal keratitis $(18 / 24 ; 75 \%)$ with fewer reporting that CXL would be at least moderately helpful as an adjuvant therapy for acanthamoeba keratitis $(11 / 24 ; 46 \%)$. No respondents believed CXL as an adjuvant therapy would be detrimental in treating bacterial ulcers, but some believed it would be detrimental for fungal $(1 / 24 ; 4 \%)$ or acanthamoeba $(2 / 24 ; 8 \%)$ ulcers.

Fewer respondents believed CXL would be at least moderately helpful to treat bacterial $(18 / 24 ; 75 \%)$, fungal $(14 / 24 ; 58 \%)$ and acanthamoeba $(10 / 23 ; 43 \%)$ as the only therapy. Some respondents felt CXL would be detrimental in treating bacterial $(2 / 24 ; 8 \%)$, fungal $(3 / 24 ; 13 \%)$ or acanthamoeba $(4 / 23 ; 17 \%)$ ulcers if used without antimicrobial treatments. More respondents felt CXL would have no effect as adjuvant or sole therapy for acanthamoeba keratitis when compared with bacterial and fungal keratitis (table 3 ).

An additional section of the questionnaire asked respondents who had experience using CXL to treat IK of each organism type about their opinions on its effectiveness in eradicating the infectious organism. Most corneal specialists $(14 / 16 ; 88 \%)$ reported CXL was helpful in eradicating bacterial ulcers, while $13 \%(2 / 16)$ reported no effect. Respondents were split on the effectiveness of CXL treating fungal ulcers in their experience, with $46 \%$ (6/13) reporting that the CXL was at least moderately helpful, but $54 \%(7 / 13)$ said the CXL had no effect in eradicating the fungus. Similarly, respondents were split on acanthamoebic ulcers as well: $50 \%(6 / 12)$ reported CXL was at least moderately helpful in eradicating the acanthamoeba, and 50\% (6/12) said the CXL had no effect. All five respondents with experience treating IK 


\begin{tabular}{|c|c|c|c|}
\hline Survey response & Helpful, n/N (\%) & No effect, $\mathrm{n} / \mathrm{N}(\%)$ & Detrimental, $\mathrm{n} / \mathrm{N}(\%)$ \\
\hline \multicolumn{4}{|l|}{ Adjuvant therapy } \\
\hline Bacterial & $23 / 24(96 \%)$ & $1 / 24(4 \%)$ & 0/24 (0\%) \\
\hline Fungal & $18 / 24(75 \%)$ & $5 / 24(21 \%)$ & $1 / 24(4 \%)$ \\
\hline Acanthamoeba & $11 / 24(46 \%)$ & $10 / 23(43 \%)$ & $2 / 23(9 \%)$ \\
\hline Unknown organism & - & - & - \\
\hline \multicolumn{4}{|l|}{ Sole therapy } \\
\hline Bacterial & $18 / 24(75 \%)$ & $4 / 24(17 \%)$ & $2 / 24(8 \%)$ \\
\hline Fungal & $14 / 24(58 \%)$ & 7/24 (29\%) & $3 / 24(13 \%)$ \\
\hline Acanthamoeba & $10 / 23(43 \%)$ & $9 / 23(39 \%)$ & $4 / 23(17 \%)$ \\
\hline Unknown organism & - & - & - \\
\hline \multicolumn{4}{|l|}{ Experience treating } \\
\hline Bacterial & $14 / 16(88 \%)$ & $2 / 16(13 \%)$ & $0 / 16(0 \%)$ \\
\hline Fungal & $6 / 13(46 \%)$ & $7 / 13(54 \%)$ & $0 / 13(0 \%)$ \\
\hline Acanthamoeba & $6 / 12(50 \%)$ & $6 / 12(50 \%)$ & $0 / 12(0 \%)$ \\
\hline Unknown organism & $5 / 5(100 \%)$ & $0 / 5(0 \%)$ & $0 / 5(0 \%)$ \\
\hline
\end{tabular}

ulcers infected with unknown organisms reported CXL was helpful in eradicating the unknown agent $(5 / 5$; $100 \%)$. Of note, no respondents reported that CXL was detrimental in their experience treating ulcers of any type of infectious organism.

\section{Cost}

Cornea specialists were asked about the proportion of their patients who were unable to undergo CXL for IK due to cost. Patients paid for the entire cost of CXL out of pocket in the practices of $39 \%(7 / 18)$ of the respondents, with an equal proportion reporting that the hospital covered the entire cost of the procedure. Other mechanisms of payment $(4 / 17 ; 24 \%)$ included cost coverage by an investigational study or a public health department. A little over half of respondents $(9 / 16 ; 56 \%)$ reported that CXL is not cost-prohibitive to any of their patients. Regardless of how the procedure was paid for, 4/16 (25\%) reported that $20 \%-50 \%$ of their patients could not receive CXL due to cost.

\section{DISCUSSION}

In this survey, we found that the majority of corneal specialists with CXL experience felt that it would be a beneficial adjuvant in the treatment of IK. There was much more consensus that CXL is beneficial in bacterial ulcers compared with fungal and acanthamoeba. In fact, most respondents reported favourable experiences treating bacterial ulcers and felt it would be effective even without antimicrobials. Most thought that the benefit of CXL was in eliminating infection, but that it may reduce corneal melting as well. Our survey revealed that $55 \%$ of the corneal specialists felt CXL was at least moderately helpful in preventing corneal thinning from their experience, while $33 \%$ felt it had no effect.
Multiple case reports have suggested potential benefits of CXL for treatment of bacterial keratitis, including resolution of resistant infection, halting of progressive melting and symptomatic improvement. ${ }^{17-20}$ One small randomised controlled trial found a benefit to CXL in the treatment of bacterial ulcers. ${ }^{14}$ In another small case series, bacterial infections resolved even though patients were treated exclusively with photochemically activated riboflavin. ${ }^{21}$ Spoerl et al reported that cornea buttons treated with CXL showed increased resistance against bacterial collagenase. ${ }^{22}$

The evidence supporting CXL for fungal and acanthamoeba keratitis is less robust. In vitro studies have shown that photochemically activated riboflavin inhibits bacterial, but not fungi growth, although when CXL was combined with amphotericin, there was an effect. ${ }^{2324} \mathrm{Clin}$ ically, Vajpayee $e t a t^{25}$ reported equivocal results of CXL as an adjuvant therapy compared with medical therapy alone in moderate fungal keratitis (defined by diameter $<6 \mathrm{~mm}$ or involving $<60 \%$ of corneal thickness) through a retrospective review. One small randomised clinical trial investigating cross-linking as adjuvant therapy for deep fungal ulcers at Aravind Eye Hospital in Madurai, India was stopped after only enrolling 13 patients due to concern that CXL was increasing the rate of perforation in severe fungal ulcers. ${ }^{15}$

Although less well studied, most agree that acanthamoeba is unlikely to respond to CXL due to the lack of demonstrated in vitro cystocidal activity. ${ }^{26}$ Published results of in vitro and in vivo animal (rabbit and hamster) studies showed ultraviolet light $\mathrm{A}$ and riboflavin treatment failed to demonstrate cystocidal activity as sole therapy. ${ }^{2627}$ However, in vitro and animal models often have high inoculation and may not reflect real life situation. On the 
other hand, case reports on acanthamoeba keratitis in humans in which CXL was used as an adjuvant therapy showed promising results in advanced cases refractory to medical treatment. ${ }^{28-31}$ These findings suggest CXL may not be an effective sole therapy for acanthamoeba, but may be useful as an adjuvant therapy potentially by limiting stromal degradation and allowing the topical therapies to eliminate the acanthamoeba. The low incidence and prevalence of the disease makes it difficult to conduct a randomised controlled trial. In a meta-analysis by Papaioannou et $a l^{32}$ results were limited to draw a conclusion on the value of CXL for acanthamoeba or fungal keratitis.

Strengths of this study include the geographic diversity of respondents, representing a broad range of experience and international perspectives. Additionally, a majority of respondents have experience using CXL to treat IK of varying aetiologies, particularly striking given that acanthamoeba and fungal keratitis are statistically rare. Limitations of this study include a lower response rate of $15.3 \%$. However, this rate is higher than other web-based international surveys of experts in ophthalmology, ${ }^{33-35}$ and the number of responses reflecting unfavourable opinions on cross-linking for IK suggest we did not only survey advocates of the treatment method. Because experts were identified through a search of published literature, experts in cross-linking for IK may have been missed if they had not published on the topic. The majority of respondents in our study work in an academic practice setting, so the results may not be generalisable to all clinical ophthalmologists. Nevertheless, specialists are likely to treat the majority of severe IK cases. Because the use of CXL for IK is currently not approved by the US Federal Drug Administration, respondents were mostly corneal specialists outside of USA, suggesting our survey may be influenced by selection and/or response bias. Additional limitations include branching logic formatting of the survey such that not all questions appeared for all respondents and those intrinsic to all surveys, including non-response bias and the possibility of recall bias.

\section{CONCLUSION}

Corneal specialists who have used CXL overall agree that it may be beneficial in the treatment of bacterial ulcers that are small to medium in size. However, the majority remain unsure regarding the efficacy of CXL on fungal and protozoan keratitis. Additionally, a quarter of respondents reported a moderate proportion of their patients could not undergo CXL due to cost, indicating that work still needs to be done to improve access to the procedure. The survey suggests that larger, well-designed randomised controlled trials would be of interest to corneal specialists to assess the efficacy of CXL as adjuvant therapy for IK.

Acknowledgements The authors would like to thank the ophthalmologists who participated in this study: V Agrawal, M Y Avila, U Celik, E Çerman, W J Dupps, Jr, T B Ferreira, G Ferrari, M Filippello, P Fournie, F Hafezi, A lovieno, W A Khan, K
Makdoumi, R Mencucci, H Nagaraja, B A Nassaralla, P Padmanabhan, R Paolo, V Prajna, M Rechichi, H Sideroudi, $O$ Sarac, L Sullivan and others.

Contributors JR-N contributed to study design and implementation, data analysis and writing of this manuscript. YCH and CAM contributed to data analysis and writing of the manuscript. TML and JK were involved in design and implementation of this study.

Funding Individual support for this study came from K23 EY025025 (JRN) and an unrestricted grant from Research to Prevent Blindness (JRN).

\section{Competing interests None declared.}

Patient consent Detail has been removed from this case description/these case descriptions to ensure anonymity. The editors and reviewers have seen the detailed information available and are satisfied that the information backs up the case the authors are making.

Ethics approval Ethical approval for this study was obtained from the University of California, San Francisco Committee on Human Research (UCSF Institutional Review Board).

Provenance and peer review Not commissioned; externally peer reviewed.

Data sharing statement De-identified survey response data can be provided on request.

Open Access This is an Open Access article distributed in accordance with the Creative Commons Attribution Non Commercial (CC BY-NC 4.0) license, which permits others to distribute, remix, adapt, build upon this work non-commercially, and license their derivative works on different terms, provided the original work is properly cited and the use is non-commercial. See: http://creativecommons.org/ licenses/by-nc/4.0/

(C) Article author(s) (or their employer(s) unless otherwise stated in the text of the article) 2018. All rights reserved. No commercial use is permitted unless otherwise expressly granted.

\section{REFERENCES}

1. WHO. WHO | Causes of blindness and visual impairment. http:// www.who.int/blindness/causes/en/ (accessed 16 Aug 2017).

2. Green MD, Apel AJ, Naduvilath T, et al. Clinical outcomes of keratitis. Clin Exp Ophthalmol 2007;35:421-6.

3. Prajna NV, Krishnan T, Rajaraman R, et al. Effect of oral voriconazole on fungal keratitis in the mycotic ulcer treatment trial II (MUTT II): a randomized clinical trial. JAMA Ophthalmol 2016;134:1365-72.

4. Prajna NV, Krishnan T, Mascarenhas J, et al. The mycotic ulcer treatment trial. JAMA Ophthalmol 2013;131:422-9.

5. FlorCruz NV, Evans JR. Cochrane Eyes and Vision Group. Medical interventions for fungal keratitis. Cochrane Database of Systematic Reviews. 49: John Wiley \& Sons, Ltd, 2015.

6. Austin A, Lietman T, Rose-Nussbaumer J. Update on the Management of Infectious Keratitis. Ophthalmology 2017;124:1678-89.

7. Lamy R, Netto CF, Reis RG, et al. Effects of corneal cross-linking on contrast sensitivity, visual acuity, and corneal topography in patients with keratoconus. Cornea 2013;32:591-6.

8. Vinciguerra P, Albè E, Trazza S, et al. Intraoperative and postoperative effects of corneal collagen cross-linking on progressive keratoconus. Arch Ophthalmol 2009;127:1258-65.

9. Tabibian D, Mazzotta C, Hafezi F. PACK-CXL: Corneal cross-linking in infectious keratitis. Eye Vis 2016;3:11.

10. Wollensak G, Spoerl E, Seiler T. Riboflavin/ultraviolet-a-induced collagen crosslinking for the treatment of keratoconus. Am J Ophthalmol 2003;135:620-7.

11. Alio JL, Abbouda A, Valle DD, et al. Corneal cross linking and infectious keratitis: a systematic review with a meta-analysis of reported cases. J Ophthalmic Inflamm Infect 2013;3:47.

12. Vatansever F, de Melo WC, Avci P, et al. Antimicrobial strategies centered around reactive oxygen species--bactericidal antibiotics, photodynamic therapy, and beyond. FEMS Microbiol Rev 2013;37:955-89.

13. Said DG, Elalfy MS, Gatzioufas Z, et al. Collagen cross-linking with photoactivated riboflavin (PACK-CXL) for the treatment of advanced infectious keratitis with corneal melting. Ophthalmology 2014;121:1377-82.

14. Bamdad S, Malekhosseini H, Khosravi A. Ultraviolet A/riboflavin collagen cross-linking for treatment of moderate bacterial corneal ulcers. Cornea 2015;34:402-6.

15. Uddaraju M, Mascarenhas J, Das MR, et al. Corneal cross-linking as an adjuvant therapy in the management of recalcitrant deep 
stromal fungal keratitis: a randomized trial. Am J Ophthalmol 2015;160:131-4.

16. Wall L. Perl language reference manual - for Perl Version 5.12.1. Network Theory Ltd, 2010.

17. Panda A, Krishna SN, Kumar S. Photo-activated riboflavin therapy of refractory corneal ulcers. Cornea 2012;31:1210-3.

18. Iseli HP, Thiel MA, Hafezi F, et al. Ultraviolet A/riboflavin corneal cross-linking for infectious keratitis associated with corneal melts. Cornea 2008;27:590-4.

19. Makdoumi K, Mortensen J, Crafoord S. Infectious keratitis treated with corneal crosslinking. Cornea 2010;29:1353-8.

20. Shetty $\mathrm{R}$, Nagaraja $\mathrm{H}$, Jayadev $\mathrm{C}$, et al. Collagen crosslinking in the management of advanced non-resolving microbial keratitis. $\mathrm{Br} \mathrm{J}$ Ophthalmol 2014;98:1033-5.

21. Makdoumi K, Mortensen J, Sorkhabi O, et al. UVA-riboflavin photochemical therapy of bacterial keratitis: a pilot study. Graefes Arch Clin Exp Ophthalmol 2012;250:95-102.

22. Spoerl E, Wollensak G, Seiler T. Increased resistance of crosslinked cornea against enzymatic digestion. Curr Eye Res 2004;29:35-40.

23. Martins SA, Combs JC, Noguera G, et al. Antimicrobial efficacy of riboflavin/UVA combination ( $365 \mathrm{~nm}$ ) in vitro for bacterial and fungal isolates: a potential new treatment for infectious keratitis. Invest Ophthalmol Vis Sci 2008:49:3402-8.

24. Sauer A, Letscher-Bru V, Speeg-Schatz C, et al. In vitro efficacy of antifungal treatment using riboflavin/UV-A $(365 \mathrm{~nm})$ combination and amphotericin B. Invest Ophthalmol Vis Sci 2010;51:3950-3.

25. Vajpayee RB, Shafi SN, Maharana PK, et al. Evaluation of corneal collagen cross-linking as an additional therapy in mycotic keratitis. Clin Exp Ophthalmol 2015;43:103-7.

26. Kashiwabuchi RT, Carvalho FR, Khan YA, et al. Assessing efficacy of combined riboflavin and UV-A light $(365 \mathrm{~nm})$ treatment of Acanthamoeba trophozoites. Invest Ophthalmol Vis Sci 2011:52:9333-8.

27. Berra M, Galperín G, Boscaro G, et al. Treatment of Acanthamoeba keratitis by corneal cross-linking. Cornea 2013;32:174-8.

28. Khan YA, Kashiwabuchi RT, Martins SA, et al. Riboflavin and ultraviolet light a therapy as an adjuvant treatment for medically refractive Acanthamoeba keratitis: report of 3 cases. Ophthalmology 2011:118:324-31.

29. Á A-G, ÁR G-O, Villa-Collar C, et al. Corneal cross-linking for Acanthamoeba keratitis in an orthokeratology patient after swimming in contaminated water. Contact Lens Anterior Eye J Br Contact Lens Assoc 2014;37:224-7.

30. Müller L, Thiel MA, Kipfer-Kauer Al, et al. Corneal cross-linking as supplementary treatment option in melting keratitis: a case series. Klin Monbl Augenheilkd 2012;229:411-5.

31. Morén H, Malmsjö M, Mortensen J, et al. Riboflavin and ultraviolet a collagen crosslinking of the cornea for the treatment of keratitis. Cornea 2010;29:102-4.

32. Papaioannou L, Miligkos M, Papathanassiou M. Corneal collagen cross-linking for infectious keratitis: a systematic review and metaanalysis. Cornea 2016;35:62-71.

33. Loh AR, Hong K, Lee S, et al. Practice patterns in the management of fungal corneal ulcers. Cornea 2009;28:856-9.

34. Sy A, O'Brien KS, Liu MP, et al. Expert opinion in the management of aqueous Deficient Dry Eye Disease (DED). BMC Ophthalmol 2015;15:133.

35. Oldenburg CE, Acharya NR, Tu EY, et al. Practice patterns and opinions in the treatment of acanthamoeba keratitis. Cornea $2011 ; 30: 1363-8$. 